\title{
Plasmacytoma Masquerading as Meningioma
}

\author{
Münibe Büşra Erdem¹, Pınar Çakmak² Nalan Akyürek² Fikret Dogulu \\ ${ }^{1}$ Department of Neurosurgery, Gazi University Faculty of Medicine, \\ Ankara, Turkey \\ ${ }^{2}$ Department of Medical Pathology, Gazi University Faculty of \\ Medicine, Ankara, Turkey

\begin{abstract}
Address for correspondence Münibe Büşra Erdem, MD, Department of Neurosurgery, Gazi University Faculty of Medicine, Emniyet Mah. Mevlana Boulevard, Besevler, Ankara 06560, Turkey (e-mail:dr.mbusra@gmail.com).
\end{abstract}

Indian J Neurosurg 2021;10:138-140.

\begin{abstract}
Keywords

- plasmacytoma

- skull neoplasms

- osteolysis

Solitary bone plasmacytoma is a rare disease in the skull. We present a 70-year-old patient who presented with a skull deformity due to the left parietooccipital tumor. Neurological examination found no deficit. The systemic scanning revealed no additional lesion. The surgery was planned, and the tumor was removed totally with the marginal bone around it. Histopathological examination confirmed solitary bone plasmacytoma. The patient is being followed-up without recurrence or progression to multiple myeloma. As the calvarial solitary bone plasmacytomas can be easily misdiagnosed preoperatively, the detailed examination of the CT features may be helpful for the planning and course of the surgery.
\end{abstract}

\section{Introduction}

Solitary plasmacytoma is a rare disease composed of colonized monoclonal plasma cells that are found in a single lesion in the body. Generally, there is no plasmacytosis in the bone marrow or only a small amount $(<10 \%){ }^{1}$ The lesion may be either in bone or soft tissue, and the disease is classified according to the location: solitary bone plasmacytoma (SBP) and extramedullary (soft tissue) plasmacytoma. ${ }^{2}$ The prevalence of SBP is dominant in males, and the peak incidence is in the 4th to 6 th decades. It has a high risk in terms of progression to multiple myeloma than extramedullary plasmacytomas. ${ }^{3}$ SBPs of the skull have been rarely reported in the literature. Here, we would like to contribute with a case presentation.

\section{Case Presentation}

A 70-year-old male patient presented to the outpatient clinic with a complaint of swelling behind the left ear that appeared over the course of a month. Neurological examination found no abnormalities. The cranial CT revealed a crescent-shaped, expansile, $83 \times 77 \times 41 \mathrm{~mm}$ extra axial lesion in the left parietooccipital region $(\boldsymbol{-}$ Fig. 1A). In the bone window of the $\mathrm{CT}$,

published online

November 19, 2020
DOI https://doi.org/ $10.1055 / \mathrm{s}-0040-1716989$ ISSN 2277-954X. the boundaries of the lesion were irregular, and the calvarial bones seemed to be destructed ( - Fig. 1D, H). The cranial MRI showed regular contrast enhancement with gadolinium in the mass lesion ( $\boldsymbol{- F i g . ~ 1 B , ~ C ) ~ T h e ~ s k e l e t a l ~ s u r v e y , ~ s e r u m ~ a n d ~}$ urine protein electrophoresis were performed and revealed no abnormality. For systemic scan, 18-fluorodeoxyglucose positron emission tomography (18F-FDG PET) was performed and any additional lesion or focus was not found in favor of malignancy. Surgical excision of the lesion was planned. During the surgery, the mass was seen after the subgaleal dissection. It was hypervascular, soft, graycolored, excisable with rounger, and easily peeled from the dura mater. There was nonpulsatile but abundant bleeding during the excision. The hemorrhage could not be controlled by electrocoagulation or bone wax, since it originated from multiple diploic vessels. When the mass was removed totally and healthy bone margins were seen, the bleeding was brought under control and decreased significantly. The dura mater and subcutaneous tissue were seen to be healthy. The bone defect was repaired by performing cranioplasty with methyl methacrylate ( - Fig. 1E, I) In the histopathological examination, the tumor cells were positive with $\mathrm{CD}$ 138 antibody, and the tumor was compatible with plasmacytoma (-Fig. 2). The patient underwent the bone marrow
(C) 2020. Neurological Surgeons' Society of India.

This is an open access article published by Thieme under the terms of the Creative Commons Attribution-NonDerivative-NonCommercial-License, permitting copying and reproduction so long as the original work is given appropriate credit. Contents may not be used for commercial purposes, or adapted, remixed, transformed or built upon. (https://creativecommons.org/licenses/by-nc-nd/4.0/).

Thieme Medical and Scientific Publishers Pvt. Ltd. A-12, 2nd Floor, Sector 2, Noida-201301 UP, India 

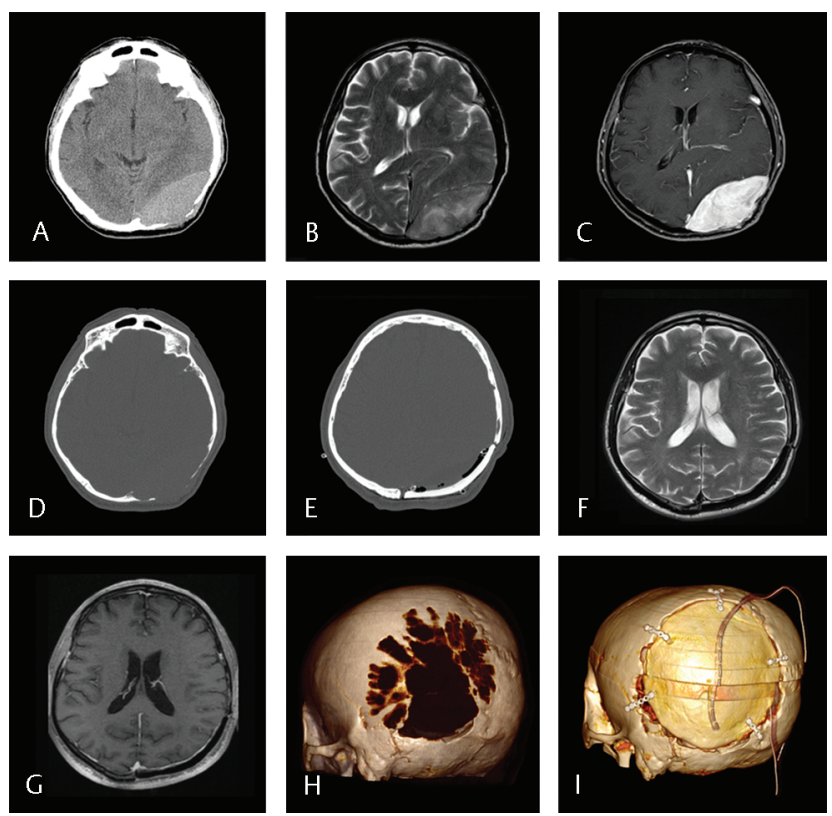

Fig. 1 Radiological images of the patient: (A) Left parietooccipital lesion in the preoperative cranial CT. (B) Preoperative T2-weighted cranial MRI. (C) Contrast enhancement of the lesion in the preoperative T1-weighted cranial MRI. (D) Perforated parietooccipital bones seen in bone window of the preoperative cranial CT. (E) Postoperative cranial CT. (F) T2-weighted cranial MRI in the second postoperative month. (G) Postcontrast T1-weighted cranial MRI in the second postoperative month. $(\mathbf{H}) 3 \mathrm{D}$ reconstruction of the preoperative CT shows the perforated skull appearance. (I) 3D reconstruction of the postoperative $\mathrm{CT}$ shows the cranioplasty with methyl methacrylate, plate, and screws.
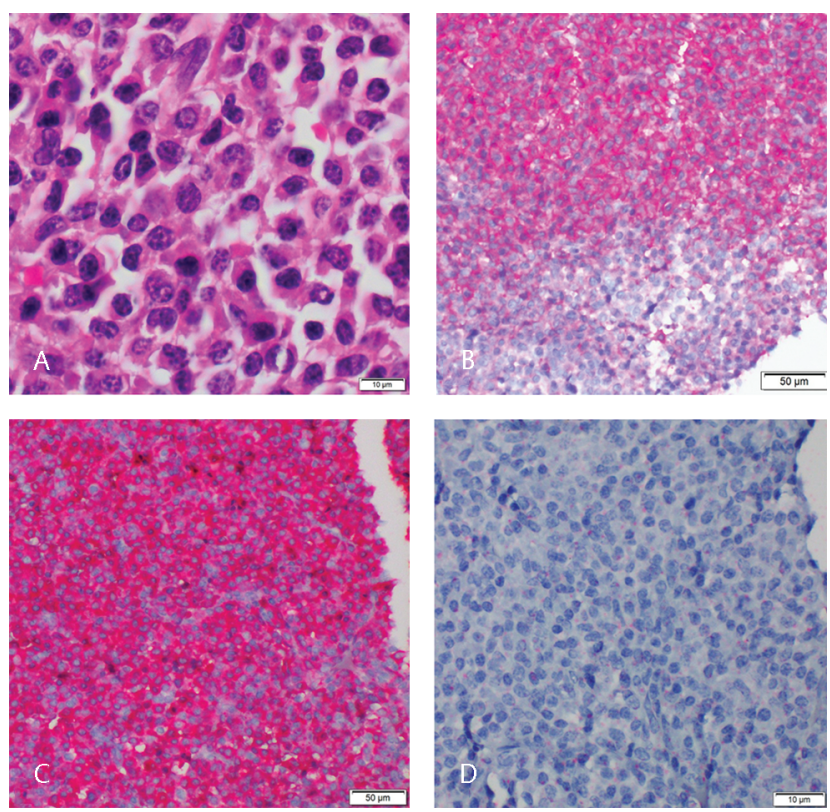

Fig. 2 Histopathological examination: (A) Plasma cells seen in the tumoral tissue. (B) Widespread positiveness with CD138 seen in immunohistochemistry. (C) Monotypic staining seen with Kappa. (D) Negativity with Lambda. biopsy. Any abnormal blast cells or plasma cell involvement was not found. The patient was discharged on the second postoperative day without any complications. With all the findings, the diagnosis was decided to be solitary bone plasmacytoma, and the follow-up of the patient was started. In the postoperative second month, there was no new mass formation in the cranial MRI ( - Fig. 1 F, G) The first postoperative year is over right now, and the patient is being followed-up without recurrence or progression to multiple myeloma.

\section{Discussion}

The cranial SBP cases in the literature could be divided into two groups: the cases located at the skull base, which is a rather complex anatomical structure (sphenopetroclival lesions), and the cases located at the cranial vault. ${ }^{4}$ We investigated the SBPs reported as being located in the calvarium by searching in the PubMed database. To date, there are 45 reported SBPs in the calvarium. (We were able to evaluate the reports whose abstract or full text are available in English.) The radiological appearance of these cases varied according to the involvement of the subcutaneous tissue, outer tabula, inner tabula, or the dura mater. They resembled an epidural hematoma due to the biconvex appearance in the $\mathrm{CT},{ }^{5}$ and a meningioma due to the contrast enhancement and proximity to the bone-dura border in the MRI. ${ }^{6}$ The clinical history is generally discordant with epidural hematoma; additionally, there is a destruction in the calvarial bones. Although the lesion seems similar to a meningioma with its solid structure and contrast involvement in the MRI, meningiomas often constitute hyperostosis instead of osteolytic lesions in the skull.7 In differential diagnosis, eosinophilic granuloma is also thought of, as it causes lytic lesions in the skull. However, in eosinophilic granulomas, the lesions are relatively regular-bordered, "punched-out" shaped with no reactive sclerosis, and there may be more than one lesion. ${ }^{8}$ Additionally, $80 \%$ of the eosinophilic granulomas occur in childhood and adolescence. In SBPs which invade both the inner and outer table but out of the dura mater, there may be a "soap bubble" appearance formed by expansile, lytic, bubbly, and septated lesion, as detected in our patient ${ }^{9-11}$ ( $\boldsymbol{- \text { Fig. }} \mathbf{1 H}$ ). It is noteworthy that the lesions did not cause reactive sclerosis. We liken this radiological appearance to a "perforated skull."

Another underlined point in the literature is the bleeding tendency of SBPs. As a result of being a hematologic malignancy and residing in the diploe, the hemorrhage that arises at the surgery may be of a significant amount. The preoperative angiographies could reveal the vascularization of the tumor in detail ${ }^{12}$ and embolization by superselective catheterization of superficial temporal, ${ }^{12}$ occipital, ${ }^{13}$ middle meningeal, ${ }^{14}$ and accessory meningeal arteries ${ }^{15}$ could be performed. In our present case, the initial diagnosis was meningioma, and we did not perform preoperative embolization regrettably. 
As the disease was localized and the mass was totally removed, our patient did not undergo radiotherapy. However, the close follow-up is still in progress. As SBPs have a risk of progression to multiple myeloma with $10 \%$ in 3 years and 65 to $84 \%$ in 10 years. ${ }^{1,3}$ Even though the total resection is performed, the close follow-up should be maintained in SBPs in terms of recurrence or progression to multiple myeloma. ${ }^{16}$

\section{Conclusion}

In this report, we tried to highlight the points of SBPs that should be kept in mind in neurosurgical practice. Although the CT images resemble extra-axial hematomas, they are often not confused due to incompatible clinical history. When the surgery is planned with only examining the MRI, much more intraoperative bleeding than a meningioma may occur. Therefore, bone changes in the CT should be examined in detail, because they may lead us to performing whole body scanning in terms of systemic disease and taking measures such as embolization to reduce the amount of intraoperative bleeding as well as.

\section{Funding}

None.

\section{Conflict of Interest}

None declared.

\section{References}

1 Caers J, Paiva B, Zamagni E, et al. Diagnosis, treatment, and response assessment in solitary plasmacytoma: updated recommendations from a European Expert Panel. J Hematol Oncol 2018;11(1):10

2 Swerdlow SH, Campo E, Pileri SA, et al. The 2016 revision of the World Health Organization classification of lymphoid neoplasms. Blood 2016;127(20):2375-2390
3 Tsang RW, Campbell BA, Goda JS, et al. Radiation therapy for solitary plasmacytoma and multiple myeloma: Guidelines from the International Lymphoma Radiation Oncology Group. Int J Radiat Oncol Biol Phys 2018;101(4):794-808

4 Gomez CK, Schiffman SR, Bhatt AA. Radiological review of skull lesions. Insights Imaging 2018;9(5):857-882

5 Rutherford SA, Leach PA, Richardson PL. Solitary skull vault plasmacytoma masquerading as an extradural haematoma. Acta Neurochir (Wien) 2004;146(8):863-864

6 Anoop TM, Jain N, Nair SG. Intracranial plasmacytoma mimicking meningioma. J Neurosci Rural Pract 2014;5(1):87-87

7 Heick A, Mosdal C, Jørgensen K, Klinken L. Localized cranial hyperostosis of meningiomas: a result of neoplastic enzymatic activity? Acta Neurol Scand 1993;87(3):243-247

8 Angelini A, Mavrogenis AF, Rimondi E, Rossi G, Ruggieri P. Current concepts for the diagnosis and management of eosinophilic granuloma of bone. J Orthop Traumatol 2017;18(2):83-90

9 Bakar B, Tekkok IH. Plasmocytoma of the skull vault. Turk Neurosurg 2012;22(1):95-98

10 Munjal S, Srivastava A, Jain S, Mehta VS. Skull vault plasmacytoma mimicking parasagittal meningioma: "mini-brain appearance.” Asian J Neurosurg 2019;14(1):231-233

11 Wilson P, Chumas P, van der Walt JD. Solitary plasmacytoma of the frontal bone. Clin Radiol 1990;42(4):289-290

12 Naganuma H, Sakatsume S, Sugita M, Satoh E, Asahara T, Nukui H. Solitary plasmacytoma of the skull: immunohistochemical study of angiogenic factors and syndecan-1-two case reports. Neurol Med Chir (Tokyo) 2004;44(4):195-200

13 Kuo Y-H, Huang W-C, Wu J-C. Surgical Treatment for a Giant Solitary Plasmacytoma with Skull Erosion. Cureus 2018;10(11):e3535

14 Pallud J, Page P, Varlet P, Roux F-X. Highly vascular solitary plasmacytoma of the calvarium. Br J Haematol 2006;133(1):2-2

15 Matsuda M, Nakazawa T, Kizuki H, Matsumura K, Nakasu S, Handa J. Solitary plasmacytoma of the skull vault-case report. Neurol Med Chir (Tokyo) 1996;36(6):388-392

16 Dimopoulos MA, Terpos E. Solitary bone plasmacytomas need to flow. Blood 2014;124(8):1209-1210 